\title{
HOW YOU LIKE MY CUT?
}

\author{
Nadia Barkate Barreiro \\ Universidad Pais Vasco / Euskal Herriko Unibertsitatea. Dpto Dibujo. Doctoranda
}

\begin{abstract}
Resumen
Peaches es pop, ella es feminismo y es performance, también es placer y es peligro. Su trabajo tiene la habilidad espectacular de resumir un largo camino recorrido por la representación del cuerpo y por la evolución del pensamiento y de la acción feministas. Su propuesta refresca las paradojas presentes en la normalización de la sexualidad e incluso las más evidentes acaban encontrando su lugar, a través de las prácticas performativas. Es un discurso complejo que comparte elementos y estereotipos con cierto imaginario popular divergente y que a su vez reflexiona con experiencia la teoría más académica del feminismo y sus grietas o contradicciones. Los tres videoclips de la artista canadiense Peaches aquí comentados, sirven como ejemplo para señalar la capacidad que tiene el arte de abrir el discurso semiótico, atajando hacia las problemáticas más fundamentales de la formulación sexo-política. Como Beatriz Preciado (2007) dijo, el nuevo feminismo es lúdico y reflexivo, es posporno, punk y transcultural.
\end{abstract}

\section{Palabras clave: SEXUALIDAD; FEMINISMO; PERFORMANCE; IMAGINARIO TRASCULTURAL; ACCIÓN POLÍTICA}

\section{HOW YOU LIKE MY CUT?}

\section{Abstract}

Peaches is pop, she is feminism and she is performance, she is pleasure and danger as well. Her work has the incredible ability to condense the long path traversed by the body as representation and the evolution of feminist thought and action. Her proposal refreshes the paradoxes present within the normalization of sexuality and thanks to that, some of them, the most obvious ones, find a new place within performative practices. Hers is a complex discourse that shares elements and stereotypes with a divergent popular imaginary and which through experience ends up reflecting on the most academic side of the theory of feminism and its own "cuts", cracks or contradictions. The three video clips by the canadian artist, Peaches, that we analyse here, serve as an example to point out the capacity that art has to open the semiotic discourse, addressing the most fundamental problems of the sex-political formulation. As Beatriz Preciado (2007) said, the new feminism is playful and reflexive, it is post-porno, punk and transcultural.

Keywords: SEXUALITY; FEMINISM; PERFORMANCE; TRANSCULTURAL IMAGINARY; POLITICAL ACTION

\footnotetext{
Barkate Barreiro, Nadia. 2017 . "How you 1ike my Cut?". AusArt 5 (1): 39-47 DOI: 10.1387/ausart.17762
}

\section{AUSART}




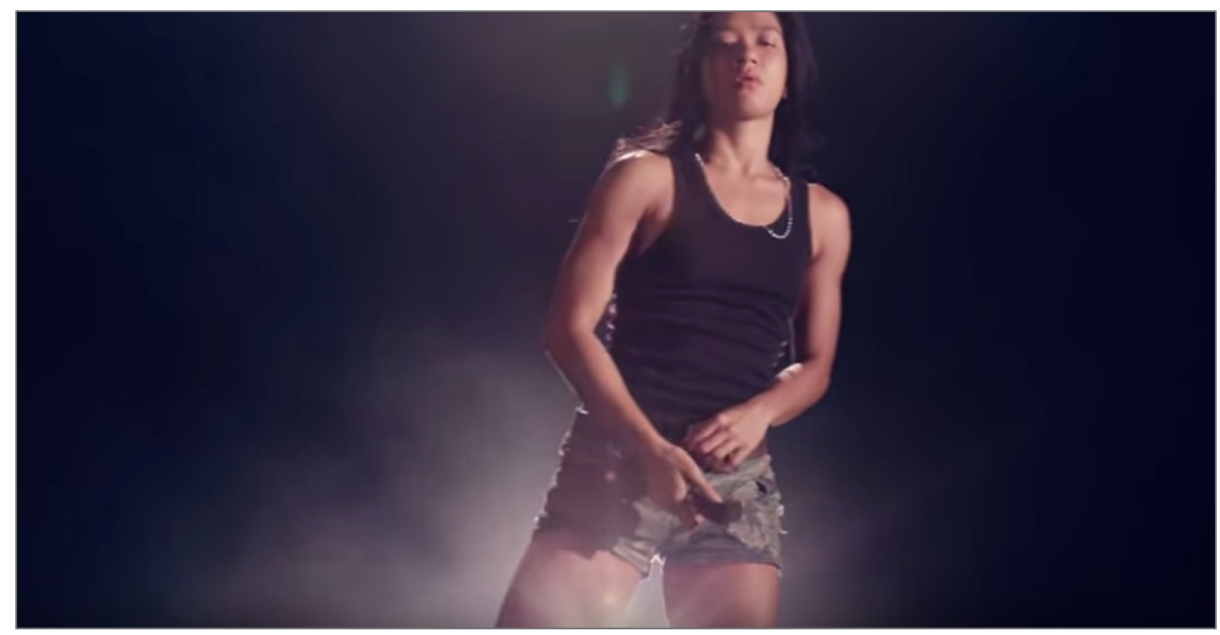

Captura del video How you like my cut? Peaches, 2015.

How you like my Cut?, es un tema de la artista y compositora canadiense Peaches, publicado durante la promoción de su disco Rub-y en 2015, y es la primera vez que ella no protagoniza un video suyo. En su lugar Elisa Jocson, una bailarina, interpreta un baile erótico denominado Macho Dancer ${ }^{1}$, que de origen era realizado por hombres para un público gay en ciertos clubs nocturnos del distrito rojo de la ciudad de Manila. En el video, como se suele hacer en estos tipos de espectáculos, la bailarina es iluminada dorsal y frontalmente al ritmo de la música y este cambio a contraluz, produce una suerte que diferencia el contorno del contenido. Las formas del cuerpo de Elisa Jocson hablan el lenguaje de un cuerpo excluido, ella danza ampliamente con los brazos ocupando la pantalla frente al fondo, que apagado deja al lenguaje desorientado en el tiempo y el espacio. Cuando de súbito la luz se enciende, vuelve el contexto del club y del show temático: la heroína de juego Tomb Rider baila, como una mujer armada de su sexo y peligrosa, y también como un stripper que somete a la mirada.

A Peaches le interesa lo queer y lo encarna, puede decirse coloquialmente que es "una chica mala". En el contexto teórico de Judith Butler, practicar lo queer no consiste en actuar conflictivamente porque sí, sino que representa una intervención específica en el sistema: la trasformación de la abyección en acción política ejecutada deliberadamente para reescribir la historia del término de la exclusión. El movimiento es hacia el progreso de la denominación, procura superar las versiones dialécticas con las que no está de acuerdo, y no desde un discurso inverso, sino desde la afirmación de lo no convencional para sustituir los términos por medio de una imposición. Una apropiación. 
Como sus propias palabras lo expresan "La afirmación pública de lo queerness representa la performatividad como apelación a las citas con el propósito de dar nueva significación a la abyección de la homosexualidad, para transformarla en desafío y legitimidad" (Butler (1993] 2002, 47).

La identidad sexual es la identidad a secas. La áspera identidad. Por ejemplo, cuando Judith Butler al comienzo de Cuerpos que importan, se introduce de esta manera, (dulcificando su nombre para desafiarse a sí misma): “ $Y$ que ocurre con la materialidad de los cuerpos, Judy? Supuse que el agregado de Judy era un esfuerzo por desalojarme del más formal "Judith" y recordarme que hay una vida corporal que no puede estar ausente de la teorización. Había cierta exasperación en la pronunciación de ese apelativo final en diminutivo, cierta cualidad paternalista que me reconstruía como una niña díscola, que debía ser obligada a regresar a la tarea, a la que había que reinstalar en ese ser corporal que, después de todo, se considera más real, más apremiante, más innegable. Quizá fue un esfuerzo por recordarme una feminidad aparentemente evacuada" ([1993] 2002, 12). Cuando habla el cuerpo validado dice: Hay una persona aquí, las preguntas se formulan la una a la otra: ¿Cuál es el lugar del sujeto?... ¿Cuál es el lugar del cuerpo?

El vídeo muestra cosas obvias: la bailarina es una mujer y el vestuario bélico pertenece a cierto imaginario sexual. Hay algo no tan claro, algo atlético que se inserta como un juego simbólico que produce un desajuste entre varios mitos análogos en lo místico y lo pagano. La interferencia es una aparición del Discóbolo, Lara Croft y una diosa antigua. Un espejismo. La luz enseña y la sombra sugiere. "La magia de la diosa tántrica Tārā que significa estrella en sánscrito, revela (proyecta) y oculta la verdad al mismo tiempo" (Campbell [1974] 2013, 77). Lo interior para comprender lo exterior. Al nombrar a Tārā, Joseph Campbell relaciona dos raíces verbales en sánscrito: la raíz trī (cruzar o atravesar, transportar, liberar) y la otra raíz stṛi (expandir, extender, difundir como la luz) de las que proviene el significado y el nombre de Tārā, de ellas derivan las palabras astro y estrella. La palabra india utilizada para ilusión es māyā, de la raíz verbal mā (medir, conformar, formar, construir, crear, mostrar o exponer) se refiere tanto al poder que crea la ilusión como a la falsa apariencia que se manifiesta y con ello lo que se oculta. Una diosa para Peaches, es por ejemplo Kim Gordon, y para conseguir sus favores, para que le deje luchar en el ring, una parodia de valkirias del feminismo, le tiene que sobornar, en otro video: Close up (2015). En este video tampoco falta el humor, Peaches pone el dedo en el centro de mi corazón, en el punto justo de estimulación. Con fragmentos de las letras de sus canciones, me hago un cuerpo nuevo, quizá 
armado de actitudes infladas e identidades corruptas pero gozando con la esperanza de la belleza de un poder ilusorio.

It's my body? Es el nombre de un conjunto de escritos de Kim Gordon (bajista de Sonic Youth), que retoma pretendidamente el título de la canción de Alice Cooper (1971). La letra dice así: "Lo que tengo, ¿Eso que te hace querer amarme?...¿ ¿Es mi cuerpo?... ¿O alguien que podría ser?, ¿Algo dentro de mí?, Será mejor que me lo digas. Dime.. Realmente depende de ti, ¿Tienes tiempo para averiguarlo?... ¿Quién soy en realidad?, ¿Qué se necesita para entrar en tu mente?". Lo andrógino estaba implícito en el rock desde que Alice Cooper lo sacó a la escena en una curiosa combinación con lo gótico, tal y como Kim Gordon cuenta, el cantante "ejemplificó lo borroso y lo confuso expresados en el rock and roll. Puedo recordar de la escuela secundaria a tantos jóvenes preguntándose si Alice Cooper era hombre o mujer. No podíamos creer que Alice fuera tal vez una travesti. O una mujer. (...) la pregunta se prolongó: "¿Qué es un cambio de sexo?, estábamos demasiado reprimidos para poder llegar a alguna conclusión, todas eran demasiado horribles. Excepto que era sólo rock and roll, hacer-creer" (Gordon 2014, 148).

El deseo está inscrito entre las variedades del espectáculo. En Peaches el apelativo queer se contextualiza en el lenguaje corporal heredado del rock, otra vez desde el show. Ya lo dijo Judith Butler (1993), el género es performativo y lo es porque sólo puede ser actuado, ya que no nos pertenece. Hablar de performatividad del género implica decir que el género es una actuación reiterada y obligatoria en función de unas normas sociales amenazadoras. Y dicha actuación está condicionada por una serie de castigos y recompensas. La persona que actúa el género no realiza necesariamente el papel que le gustaría, sino que logra hacer lo que puede, bajo la mirada del modelo de legitimación heterocéntrico. En este modelo los supuestos llevan la carga de un exceso de significación para poder determinarse. Actuar el género es responder a ese exceso. Los clichés mas viejos permanecen, por ejemplo, aquellos entre los que Alice Cooper habría tomado su versión gótica de lo andrógino, sin embargo para poder robar esas prendas, tuvo que tomarse algunas licencias.

Entre ellas, quizá re-nombrar un espacio nuevo para la sexualidad diferente del antiguo. Un espacio que ya había Platón "designado a la mujer con la aporía de la chora: espacio matriarcal, nutrición, innombrable, anterior a Uno, a Dios y por consiguiente que desafía a la metafísica" (Kristeva 1995, 188). Mucho después, Julia Kristeva re-definió la chora semiótica como una "musicalidad infra-lingüística que apunta a todo el lenguaje poético, deviene la finalidad 
principal de la poesía moderna, una psicosis experimental" (Kristeva 1999, 23). Es importante entender que éste no es un espacio-que-contiene-algo, sino una espacialidad desprovista de la dicotomía tiempo-espacio/objeto-sujeto, en el que el signo lingüístico aún no denomina un objeto determinado. Kristeva se refiere a esto como una especie de Edén del signo inocente.

Me parece que lo que hace Peaches (y puede que Alice Cooper) es fabricarse un cuerpo travesti dentro de la chora del Glam, amando efectos y objetos, ¿Qué importa si hacen canciones, o arte, o discursos?. Lo que importa es la fascinación de las cosas que subsisten en un espacio primigenio justificado por destellos obnubilantes de poder intacto. Laderas de superficies de satén brillante, resbaladizas cascadas astrales, y algunas formas felinas y reptilianas, quizá adormecidas envueltas en terciopelos debajo de árboles llenos de frutos, recogidos para adornar el cuerpo. Fuentes y también machos fertilizadores con las plumas abiertas bajo las estrellas. Luz lejana y estereotipos brillantes. Alegorías de signos no más contradictorios están flotando en la chora, o desplazados por el viento. Los movimientos del baile son nuevas composiciones, ni en contra ni a favor del sentido, el disco suena al revés y es música, lineas locas de Matisse y de Nancy Spero. Las pistas se solapan o se dan la vuelta como un guante, se anversan y se reversan. Adán y Eva. Hacerse un cuerpo nuevo y dialogar con él. Ser hermafrodita. El diálogo es con una misma. Ser dos, como para Luce Irigaray (1998), es ser yo y tu, y hablar con el sexo, magma violento y ley del deseo. Sujetos y objetos polares, ser antípodas sexuales. Ser provocación. Ser anverso y atracción. Ser repulsión y ser inocente. El turbante no hace al fakir, pero Peaches utiliza un láser. Fuente cibernética y paraíso. Ungüentos deliciosos y abyectos son papillas de afecto. Peaches usa cemento fresco y fraguan las gratitudes de su vulgaridad.

Turgente es la carne bajo el foco, la boca se hace agua y parece que viene a cuento una anécdota. Hace poco, me vi envuelta en una reunión (una cena) de profesionales de la música y del audiovisual, y en un momento dado de la conversación, la directora del ciclo de cine documental Dock of the Bay, Eva Rivera, dijo que apenas se había encontrado en sus diez años de experiencia con el festival, con mujeres dedicadas a la crítica. Hubo varias respuestas masculinas, una de ellas fue más o menos así: "El mundo de la crítica es una perdida de tiempo y la mujer es demasiado inteligente para meterse en él". Otra menos irónica, consistió en nombrar el tópico y posible certeza de que "a las mujeres no se les ha hecho un sitio en él". También se dijo que la figura requiere no sólo "criticar por criticar", sino de enriquecer o "transmitir una experiencia" para "orientar", incluso a veces dejarse llevar por la subje- 
tividad de "sus emociones", y que quizá esto último sea lo que produzca las críticas más valiosas, pero por otro lado los mismos que hablaban aseguraban no saber definir de una forma concreta lo que ha de ser la crítica. Aunque se referían a un campo profesional muy concreto (el de la música), que hoy me es prácticamente ajeno, no impedía que me plantease una pregunta.

Parece estar asumido que ser crítico requiere de una actitud estética. ¿Y qué es actitud estética?. La actitud de un espectador activo que como tal, se impone, hace irrumpir la opinión a través de un texto o del cuerpo, la crítica coincide en algún sitio con la provocación. También es hacer-creer. Y la pregunta que se me había ocurrido antes era: ¿Cómo no puede ser entonces terreno de la inteligencia femenina? Veo que Peaches hace crítica y que lo hace de la mejor forma que lo puede hacer, en ella presentada, como un logro inherente. Ser mujer es ser provocación, es insultar y ser insultada, en un amplio espectro de acción. A veces es un poder, y otras una recriminación, un reproche del poder. Ser mujer es ser crítica, y estar en una situación crítica.

Sin profundizar más, la diferencia sexual en el trabajo y en el poder, es un tema tan coloquial y cotidiano como el sabor de boca que me queda al recordar esta anécdota, que ahora escucho How you like my cut ? como himno para entrar en el refugio, en el limbo ya, el estribillo se convierte en un mantra: corte-raja-grieta-corte-raja... Cut ofrece mas de dos sentidos. ¿Corte escénico?, ¿cuts como canciones?, o ¿rajas y referencias a la genitalidad femenina como en el álbum Cut (1977) de la banda de punk femenina y londinense The Slits ?. Esta claro que abarca todos esos significantes. Viendo otro vídeo más antiguo, Set it off (Peaches 2010), pienso que como mujer todo esto que me muestra, me molesta y siento alivio cuando ella baila y gesticula, frunce el ceño y "pone morritos", y yo ya no quiero pensar más en dificultades y ahora tira de mí el trabajo de Peaches. Enseña con placer. Me pierdo entre dos placas de hueso. Me ducho bajo el chorro que escupe entre el espacio de sus dientes separados, por ahí a Peaches se le escapa el aire. Silba y detrás la segunda puerta entre las perlas separadas de Madonna, por donde brota la rudeza de Moe Tucker. La sigue y se aproxima el rostro de nieve que se le escapa tanto que la vagina se hace oro y champán. Sale de ahí mismo y está a punto de pasar, un abrigo peludo que acaba siendo el vellocino de Angela Davis. Mientras tanto, en otras pantallas, el cuerpo decapitado baila el club en lenguaje de signos. Esta ha sido mi experiencia. También he sentido que me arrullaba la voz hasta desdoblarme en somos. Ser más de dos, ella también es yo. Peaches es ser nosotras, separadas y esparcidas por lo negro. Ella, tú y yo en el Edén de la dicción. Ella que sólo pone mimo en la repetición irónica de aquellas frases, 
consigue quitarles peso, para dejarnos bailar la resignación a nuestro ritmo: "Hijos de puta quieren pillar conmigo, acostarse conmigo, amar conmigo, todo bien... Dejémoslo, (...) Vamos, lo sabes, te encanta, lo quieres, lo tienes, te encanta...".

La Peaches es cruda y su descaro es vibrante, incita en estos momentos a querer actuar también el texto. No es cosa ligera, su provocación es histérica y me resulta asertiva. Es bruta y doméstica, no es una actuación cualquiera. La mujer no está "al borde de un ataque de nervios", sino que el mundo se disloca porque su sexualidad está en juego en una zona de misterios. Pertenece a los enigmas. Para Freud y para el psicoanálisis, las preguntas básicas de la histérica son dos: “¿A quien amo, a él o a ella?, y ¿Qué quiere decir que sea yo mujer?" (Massota 2006, 41). Identidad y sexualidad son dos significantes importantes. Destino y oráculo. La tendencia sexual es difícil de determinar. Saber naranja y objeto violeta.

La histeria debe ser entendida en su complejidad. Para no caer en los clichés sobre la naturaleza histérica de la subjetividad femenina, Zizek (2001) propone tomarla en serio y no "como un barboteo confuso incapaz de enfrentarse con lo real". Hay que entenderla como esa protesta radical que resulta de sí y para sí, por lo que hay que evitar el tópico de elevar falsamente la histeria a rango de protesta del "lenguaje corporal de la mujer contra la dominación masculina"-ya que no es un discurso inverso, sino que -"a través de síntomas histéricos, el sujeto femenino señala su rechazo a actuar como una pantalla o un medium vacío para el monólogo del hombre" (Zizek 2001, 97).

No es un monólogo. Judith Butler quería dejar hablar a los cuerpos excluidos y olvidados por "lo normativo", lo que pretendía era resignificar radicalmente la esfera simbólica, "hacia un futuro con más posibilidades de expandir la significación misma de lo que en el mundo se considera un cuerpo valuado y valorable" (Butler (1993] 2002, 46)

No es un monólogo, porque no se puede ajustar el discurso a una mujer por todas, ni generalizar una situación, ni siquiera proponer un lugar común. Beatriz Preciado, nos ofrece la visión de un feminismo que ha hecho un largo viaje, representando todas las condiciones posibles que han afectado a la mujer y en conjunto a sus privaciones sociales por orden de aparición dejando para el final los problemas del margen: trabajo, maternidad, raza, estrato económico, orientación sexual, religión... El debate sobre como debía de abordarse la sexualidad, siempre estuvo en la mesa, las hubo abolicionistas con la sexua- 
lidad, es decir anti-pornográficas. La ensayista, activista y por cierto, crítica musical, Ellen Willis (Nueva York, 1941) fue la primera en poner el término "prosexo" en la mesa del feminismo, llamando así a "este movimiento sexo-político que hace del cuerpo y el placer de las mujeres plataformas políticas de resistencia al control y la normalización de la sexualidad" (Preciado 2007). Como ella misma concluye, este nuevo feminismo "posporno, punk y transcultural", sería lúdico y reflexivo, y en cierta manera paralelo al del ámbito académico. Con mirada divergente y amante de un discurso semiótico abierto y bebiendo referencias estéticas de rincones recónditos de la cultura popular y el underground, como del mundo del cine de terror, los mitos paganos, la música punk y el imaginario ciber-punk, el cómic manga, y "encontrando en la producción audiovisual, literaria o performativa sus espacios de acción"

\section{Referencias}

Butler, Judith. (1993) 2002. Cuerpos que importan: Sobre los límites materiales y discursivos del sexo. Traducción Alcira Bixio. Barcelona: Paidos

Campbell, Joseph. (1974) 2013. Imagen del mito. Traducción de Roberto R. Bravo. Gerona: Atalanta

Gordon, Kim. 2014 . Its' my body?: Selected texts. Berlin: Stenberg

Irigaray, Luce. 1998. Ser dos. Traducción de Patricia Wilson. Buenos Aires: Paidós

Kristeva, Julia. 1995. Las nuevas enfermedades del alma. Traducción de Alicia Martorell. Madrid: Cátedra

Kristeva, Julia. (1999) 2006. El genio femenino: Hannah Arendt. Traducción de Jorge Piatigorsky. Buenos Aires: Paidós

Masotta, Oscar. (1965) 2006. Lecciones de introducción al psicoanálisis. Madrid: Gedisa

Peaches. 2015. "How you like my cut?". Vídeo de Youtube, 3:25. 14 febrero. https://www.youtube.com/watch?v=jhYF2qeMyRA

Peaches. 2009. "Set it off". Vídeo de Youtube, 3:11. 14 febrero. https://www.youtube.com/wat$\mathrm{ch} ? \mathrm{v}=\mathrm{tYg} 3 \mathrm{aHT} 8 \mathrm{vGc}$

Peaches. 2015. Close up. Vídeo de Vimeo. 3:31.17 marzo https://vimeo.com/136691919.

Preciado, Beatriz. 2007. "Mujeres en los márgenes". El País-Babelia, 13 de enero. http://elpais. com/diario/2007/01/13/babelia/1168648750_850215.html

Žižek, Slavoj. 2011 "La política de la diferencia sexual”. La página 45-46:85-97. Número monográfico "Lacan y la cultura hoy" 
Notas

${ }^{1}$ Macho Dancer es también una película de Lino Brocka, realizada en Filipinas en 1988. La historia refleja la vida de un adolescente abandonado por su amante americano que baja de las montañas para conseguir dinero a Manila, donde acabará introduciéndose en el distrito rojo y en el ambiente nocturno de los clubs gay de la ciudad.

(Artículo recibido 21-04-17; aceptado 09-06-2017) 